\title{
Transient Acantholytic Dermatosis (Grover's Disease) in a Bulgarian Patient Associated With Idiopathic Low-Grade Thrombocytopenia: First Description in the Medical Literature!
}

\author{
Georgi Tchernev ${ }^{1 *}$, Konstantin Stavrov ${ }^{2}$, Uwe Wollina ${ }^{3}$ and Ivanka Temelkova ${ }^{1}$ \\ ${ }^{1}$ Medical Institute of Ministry of Interior (MVR), Department of Dermatology, Venereology and Dermatologic surgery, \\ General Skobelev 79, 1606. Onkoderma- Clinic for Dermatology, Venereology and Dermatologic Surgery, General Skobelev 26, 1606 Sofia. \\ ${ }^{2}$ Medical Institute of Ministry of Interior (MVR),Department of Dermatology, Venereology and Dermatologic surgery, \\ General Skobelev 79, 1606 Sofia. \\ ${ }^{3}$ Department of Dermatology and Allergology, Stadtisches Klinikum Dresden, 01067, Dresden, Germany.
}

Received: July 17, 2019; Accepted: July 23, 2019; Published: July 26, 2019

*Corresponding author: Prof. Dr. Georgi Tchernev, Medical Institute of Ministry of Interior (MVR), Department of Dermatology, Venereology and Dermatologic surgery, General Skobelev 79, 1606. Onkoderma- Clinic for Dermatology, Venereology and Dermatologic Surgery, General Skobelev 26, 1606 Sofia; E-mail: georgi_tchernev@yahoo.de

\begin{abstract}
Grover's disease is a transient acantholytic dermatosis that usually disappears within a few weeks, but it can also be presented as a persistent variant with a duration of more than 3 years. The etiology of this disease is not entirely clear and possible causes include viral infections, drug reactions (BRAF inhibitors and allogeneic haematopoietic stem cell transplantation). In terms of treatment, topical and systemic steroids, oral vitamin A and PUVA therapy are described. We present a 79-year-old man with a 1-month complaint for a recurring, highly itchy, blistering rash on the skin of the upper limbs, back and chest. During the clinical examination, there was an erythemo-papulo-vesicular polymorphic rash, in places with xerosis areas, engaging the upper part of the trunk, as the initial data and subsequent histopathological verification data spoke undoubtly in direction of acantholytic dermatosis or Grover's disease .During hospitalization, systemic antihistamine and topical steroid therapy was performed. Subsequently, ambulatory therapy with Acitretin 20 $\mathrm{mg}$ /daily per os and Methylprednisolone aceponate $0.1 \%$ x 2 / daily topically was given with a good therapeutic response. We believe that this case seems to be the first officially documented case of Morbus Grover associated with idiopathic low-grade thrombocytopenia.
\end{abstract}

Key words: Morbus Grover; Idiopathic thrombocytopenia; Acitretin; Prednisolone; PSA

\section{Introduction}

By definition, Grover's disease is a transient acantholytic dermatosis that is clinically characterized by the appearance of papules or papulovesicles mainly on the trunk and most commonly affecting men between 40 and 50 years [1-3]. The definition of "transient" disease emanates from the fact that the disease usually disappears within weeks or has a duration less than three months [2,3]. However, the likelihood of long-term clinical manifestation (more than three years) in the context of persistent dermatosis, as a variant of transient acantholytic dermatosis, is also indicated [4].

\section{Case Report}

We present a case of a 79-year-old man who was hospitalized on a 1-month complaint for a recurrent, severe itchy, blistering rash on the upper limbs, back and chest (Fig.1a- 1f). The patient suffers from arterial hypertension and benign prostatic hyperplasia for which he accepts Bisoprolol $5 \mathrm{mg}(1 / 2-0-0)$, Acetylsalicylic acid $75 \mathrm{mg}(0-0-1)$, Alfuzosine hydrochloride (0$0-1)$ and Finasteride $5 \mathrm{mg}(0-0-1)$. During the dermatological examination the presence of erythemo-papulo-vesicular polymorphic rash was identified, with areas of xerosis, which involved the upper part of the trunk (Fig. 1a- 1f). Clinically, the data were indicative for acantholytic dermatosis or Grover's disease. Additionally, a blue- like lesion, located in presternal area was observed, clinically suspected for nevus blue (Fig. 1e). Paraclinical data have shown the presence of thrombocytopenia $\left(118.0 \mathrm{x} 10^{\wedge} 9 / \mathrm{l}\right)$, lymphocytopenia $(19,6 \%)$, granulocytosis $(74,3 \%)$, elevated uric acid $(440.0 \mu \mathrm{mol} / \mathrm{l})$ and triglycerides levels $(1,8 \mathrm{mmol} / \mathrm{l})$, and an increased rate of erythrocyte sedimentation $(30 \mathrm{~mm} / \mathrm{h})$. A skin biopsy was taken as the histological study showed evidence of acantholytic dyskeratosis, intraepidermal vesicular dermatitis, and confirmed the initial diagnosis, namely Grover's disease Fig 2. Due to anamnestic data of elevated PSA levels in the past $(19,94 \mathrm{ng} / \mathrm{mL})$ there was a doubt about a paraneoplastic Grover's disease. Urologic consultation and PSA control (4.32 ng/mL) was conducted, as a result of which 

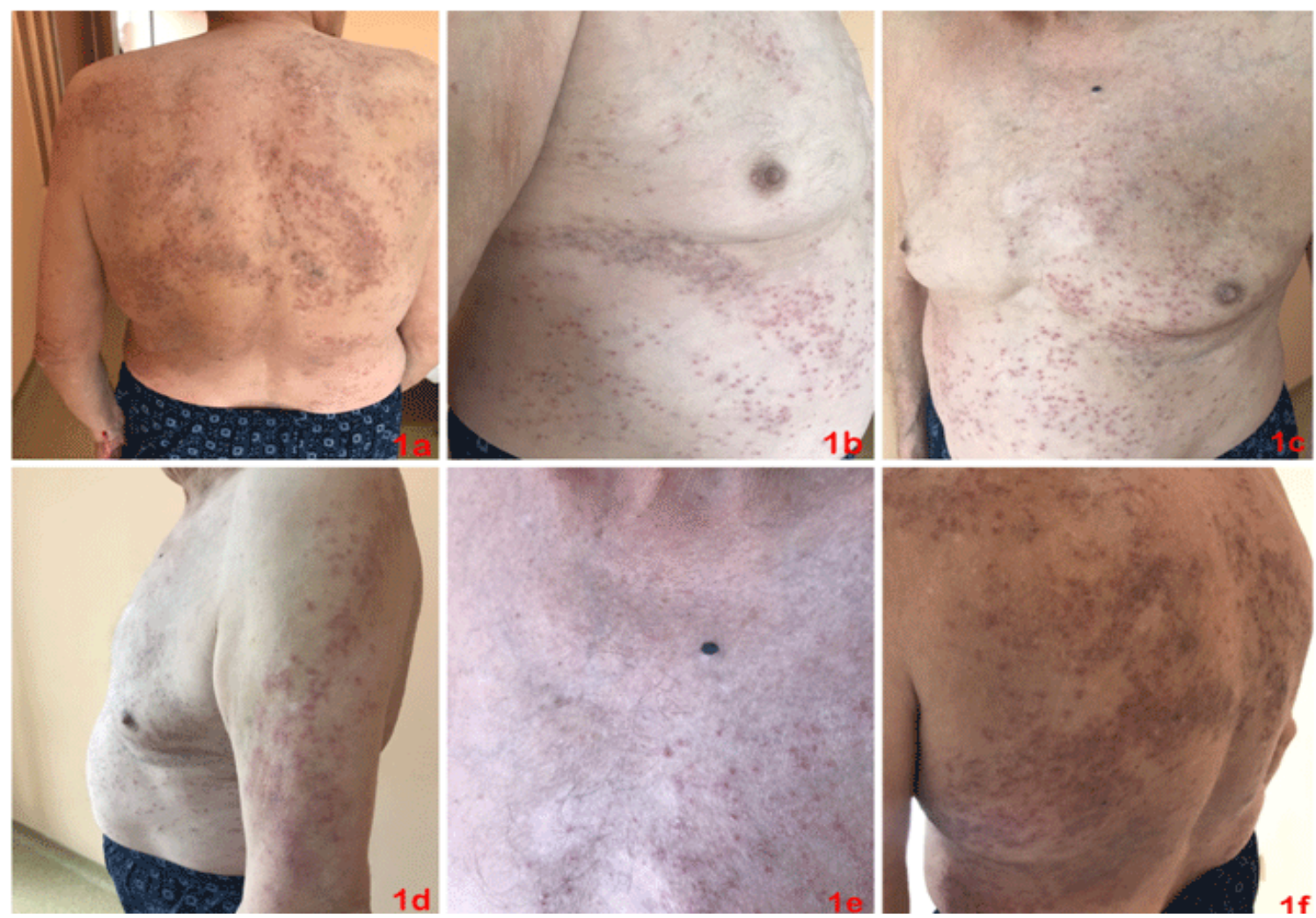

Figure 1: Clinical aspect: erythemo-papulo-vesicular polymorphic rash, with livid color, located on the back (a, f), lateral part of the trunk (b), chest and abdomen (b, c, e) ), in places with areas of xerosis. In presternal area a blue- like lesion is observed, clinically suspected for nevus blue (e).

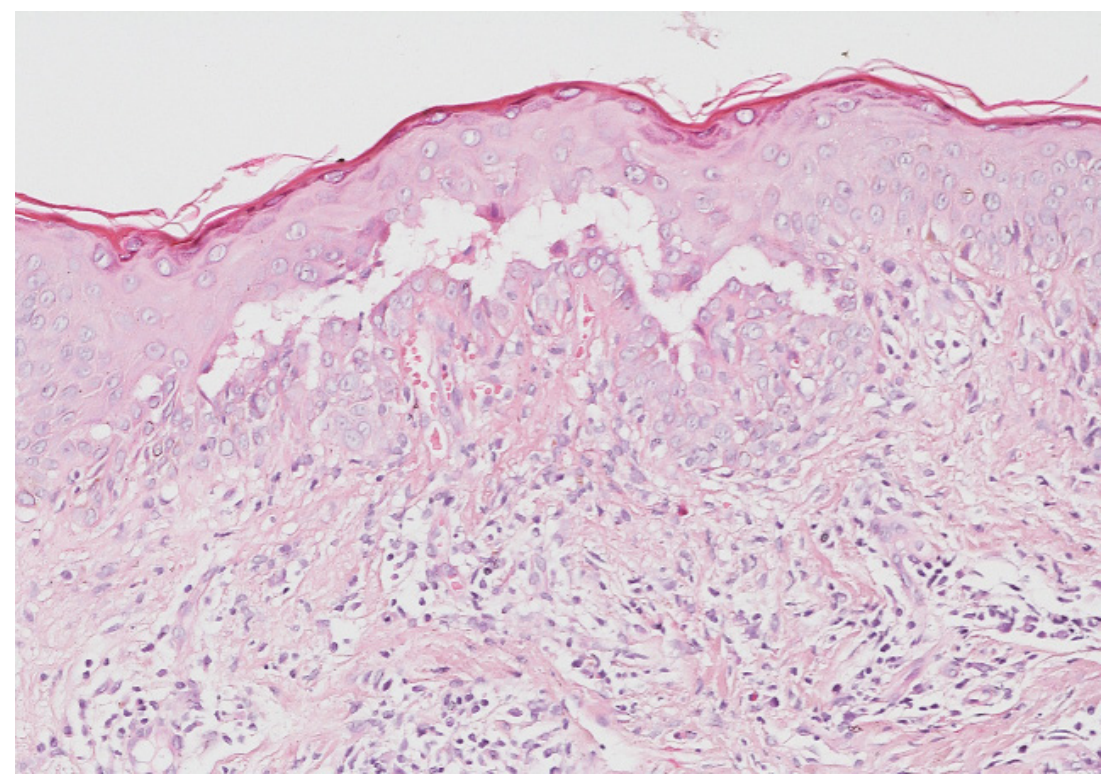

Figure 2: Intraepithelial clefting with acantholysis. Slight infiltrate with few eosinophils.x200, Histopathology performed by Prof Dr Michel Tronnier, Hildesheim, Germany, 2019. 
the presence of prostate cancer was excluded. In connection with thrombocytopenia, a hematologist was consulted with the conclusion that it was a low-grade thrombocytopenia without the need for treatment. During the hospitalization systemic therapy with Desloratadine $5 \mathrm{mg}$ /day was performed and Flumetasone pivalate / Neomycin sulphate x1/ daily was topically administered. After dehospitalisation, treatment with Acitretin $20 \mathrm{mg} /$ day per os and Methylprednisolone aceponate $0.1 \%$ x 2 / daily topical under ambulatory conditions was initiated.

\section{Discussion}

The pathogenesis of Grover's disease has not been fully elucidated and currently, etiologically, viral infections, drug reactions (under treatment with BRAF inhibitors such as vemurafenib or dabrafenib) as well as allogeneic haematopoietic stem cell transplantation (AHSCT) are reported as possible causes $[1,5$, and 6]. Histologically, the disease is characterized by 4 different acantholytic patterns, namely Darier-like type, Hailey-Hailey-type, pemphigus (vulgaris or foliaceus) -type, or spongiotic-acantholytic type. It is possible to observe a certain histological subtype, but in most cases two or more of these patterns is found [2-3].

Although in most cases the disease is presented as a benign and self-limiting condition it is possible to observe forms of extensive or atypical Grover's disease [7]. In these patients, immunosuppressant is believed to play a key role [7].

According to the prevailing part of the literature data, Grover's disease is very often combined with other dermatological and nondermatological conditions, therefore histological examination is considered to be of primary importance for distinguishing other concomitant disorders [1]. This is mostrelevant to extensive forms of Grover's disease, due to the fact that underlying malignancy, including hematopoietic malignancies, is often observed in these cases and the possibility of mistaken initiation of corticosteroid or immunosuppressive therapy should be avoided [5,7]. Currently, treatment options for transient acantholytic dermatosis include the administration of topical and systemic adrenal steroids, high doses of oral vitamin A with satisfactory results or PUVA therapy [8].

\section{References}

1. Joshua Weaver and Wilma F. Bergfeld . Grover Disease (Transient Acantholytic Dermatosis). Archives of Pathology \& Laboratory Medicine: September 2009;133(9):1490-1494.

2. Wolff H. [Transient acantholytic dermatosis (Grover)]. Hautarzt. 1977;28(2):78-82.

3. Chalet M, Grover R, Ackerman A. Transient acantholytic dermatosis: a reevaluation. Arch Dermatol.1977;113(4):431-435.

4. Simon RS, Bloom D, Ackerman AB. Persistent acantholytic dermatosis. A variant of transient acantholytic dermatosis (Grover disease). Arch Dermatol. 1976;112(10):1429-1431.

5. Lim PPL, Fernandez Penas P, Gottlieb D. Transient acantholytic dyskeratosis (Grover's disease) after bone marrow transplantation. Australas J Dermatol. 2016;57(4):e120-e122. Doi: 10.1111/ajd.12517

6. Sabatier-Vincent M, Charles J, Pinel N, Challende I, Claeys A, Leccia MT. [Acantholytic dermatosis in patients treated by vemurafenib: 2 cases]. Ann Dermatol Venereol. 2014;141(11):689-693. Doi: 10.1016/j. annder.2014.09.024

7. Gantz M, Butler D, Goldberg M, Ryu J, McCalmont T, Shinkai K. Atypical features and systemic associations in extensive cases of Grover disease: J Am Acad Dermatol.2017;77(5):952-957.Doi: 10.1016/j. jaad.2017.06.041

8. Paul BS, Arndt KA.Response of Transient Acantholytic Dermatosis to Photochemotherapy. Arch Dermatol. 1984;120(1):121-122. 